\title{
STUDIES ON CONCURRENT SENSITIZATION AND TRYP- SINIZATION WITH THE DEVELOPMENT OF A SIMPLE TRYPSIN TUBE TEST FOR ROUTINE RHESUS GROUPING AND AS A SCREENING TEST FOR INCOMPLETE ANTIBODIES
}

\author{
BY \\ N. A. F. YOUNG \\ From St. Margaret's Hospital, Epping, Essex
}

(RECEIVED FOR PUBLICATION MARCH 26, 1957)

In their original publication Morton and Pickles (1947) described the use of trypsin for the detection of incomplete anti-R $\mathrm{h}$ antibodies. They found that it caused cells sensitized with an incomplete antibody to agglutinate, and also that it enhanced the specific agglutination of other haemagglutinins in the absence of any detectable antibody of the incomplete type. Preliminary trypsinization of test cells followed by their incubation with sera containing incomplete antibodies proved highly sensitive and specific, saline suspensions of such "trypsintreated cells" being readily agglutinated by incomplete antibodies. They mention that when trypsin was added to the serum-cell mixture, i.e., concurrent action of enzyme and antibody, its action was inhibited by the natural trypsin inhibitor present in all sera (Delezenne and Pozerski, 1903). This effect could, however, be overcome by the addition of excess enzyme.

Subsequently, in the Journal of Clinical Pathology (Morton and Pickles, 1951), the same two authors give details of the development and standardization of their proteolytic enzyme test, and follow this with an assessment of its value in the light of their experience gained during a two-year trial study. Their procedure of preliminary trypsinization with subsequent sensitization has remained as the standard method for the performance of the trypsin test. They found that it gave reliable results and was more sensitive than either the albumin or antihuman globulin methods in the detection of weak anti-D antibodies, and they concluded that: "The ease of interpretation, and the clear-cut results obtained when the results of other tests are equivocal, have led us to use the P.E. test as the final arbiter as to whether anti-D antibodies are present or not."
It is therefore surprising to find that this highly sensitive and reliable test does not seem to have gained the popularity it merits, nor to have come into general use in a number of pathological departments where routine blood grouping and antenatal supervision are carried out. This means that undue reliance is placed upon the Coombs A.H.G. test to define weak sensitization, and it is well recognized that this reagent is notoriously temperamental and liable to sudden unexpected deterioration in potency. Furthermore, in the study of antibodies other than anti-Rh, it has been frequently demonstrated that the results of the Coombs and trypsin tests, while agreeing in the majority, do not strictly parallel one another. For this reason, as recommended by Dacie (1954), these two tests should be considered as complementary to and not as substitutes for, one another. This applies particularly to haemolytic conditions of warm or cold auto-antibody types, in which the enzyme test is extremely sensitive and may detect an antibody when the results of other tests are negative.

For indirect testing corresponding to the indirect Coombs test the accepted trypsin technique is convenient, since the requisite test cells can be trypsinized in bulk, and then used for checking all the sera to be tested. It does, however, involve two separate incubation periods.

For the testing of a variety of unknown cells against a known incomplete serum such as albumin anti-D, or for checking the reactions of an unknown antibody against a battery of cells of known genotypes, the standard trypsin test is time-consuming, because it involves the preliminary trypsinization of the individual groups of cells to be tested. 
Potent " albumin agglutinating sera" are much more prevalent than "saline" ones, and certainly more readily obtainable overseas, and it was this fact which originally led to the investigation of the possibility of modifying the usual trypsin procedure in order to make it quicker and more convenient, thus widening the field of its routine application.

As the result of experimental studies, two methods have been evolved which are simple and easy to perform, involving the minimum of manipulations, and giving highly sensitive and reliable results. In the first, referred to as the "trypsin-saline test," the trypsin agglutination reaction takes place in a saline medium. In the second, referred to as the " trypsin-albumin-plasma test" increased sensitivity is obtained by allowing the reaction to proceed in a protein medium.

These two tests have proved themselves to be as sensitive and as reliable as the standard trypsin test, and their adaptation to routine clinical studies with an evaluation of their uses will be given later, together with the results obtained during a trial period when they were compared with other methods.

\section{Materials and Methods}

(1) Crystallized trypsin (Armour Laboratories).

(2) $\mathrm{N} / 20 \mathrm{HCl}$. Concentrated $\mathrm{HCl}$, sp. gr. 1.18, $0.85 \mathrm{ml}$., is dissolved in $200 \mathrm{ml}$. distilled water.

(3) $\mathrm{pH} 7.7$ phosphate buffer.
A. $\mathrm{Na}_{2} \mathrm{HPO}_{4} \cdot 12 \mathrm{H}_{2} \mathrm{O}$..
. $\quad 4.11$ g. $\%$
B. $\mathrm{NaH}_{2} \mathrm{PO}_{4} \cdot 2 \mathrm{H}_{2} \mathrm{O} \quad$..
.. $2.34 \mathrm{~g} . \%$

For use, 90.5 parts of $\mathrm{A}$ are mixed with 9.5 parts of $\mathrm{B}$. The mixture keeps well for weeks at bench temperature.

(4) Albumin-plasma Mixture. Four parts oxalated plasma and 1 part $20 \%$ bovine albumin are required and diluted $1: 1$ with saline for use.

(5) Stock Trypsin Solution. A 3\% solution is made by dissolving $300 \mathrm{mg}$. of the crystallized trypsin in $10 \mathrm{ml}$. $\mathrm{N} / 20 \mathrm{HCl}$. This keeps well for four to six weeks stored in the refrigerator.

If the mixture of trypsin and buffer solution is made while the trypsin solution is still cold, turbidity due to precipitation of phosphates occurs. This redissolves as the mixture warms up and can be hastened by placing the solution in a water bath. This latter is not imperative since the use of the solution while still turbid does not appear to interfere with the agglutination reaction.

(6) Test Trypsin Solution. This is prepared freshly each day from the stock using the phosphate buffer solution as diluent. The optimal strength for the tests was found to be $1.2 \%$, giving a final trypsin concentration of $0.48 \%$ in the serum -cell mixture with the techniques used.
A capillary constant-drop pipette is used for measuring volumes.

Red cells used in tests are washed twice in saline and made up to approximate $10 \%$ saline suspensions.

All tests and controls are set up in $3 \times \frac{3}{8}$ in. rimless test-tubes and incubated in metal racks in a water-bath at $37^{\circ} \mathrm{C}$. for two hours.

The following have been used and will be further discussed in this paper:

Routine Rhesus Grouping.-The sensitivity of this test is such that an albumin anti-D grouping serum with a trypsin titre not less than 1:64 may be used diluted 1:10 in saline for detection of all D + bloods (see reference to Du bloods later). Two volumes diluted anti-D serum are placed into a tube with 1 vol. of $10 \%$ suspension of red cells to be tested, and 2 vol. $1.2 \%$ trypsin is added.

Routine Antibody Screening Test for Antenatal Cases.Two volumes of each serum for test are placed in a tube, with 1 vol. of the appropriate test cells $\left(R_{1} R_{i}, R_{1} r, r r\right.$, etc. $)$ and 2 vol. of $1.2 \%$ trypsin added to all tubes.

Titration of Incomplete Antibody.-Titrations are performed in saline and albumin-plasma media. Doubling serial dilutions of the serum for test are made in saline and albumin-plasma mixture. Two volumes of each serial dilution are placed in separate tubes and to each are added 1 vol. of the appropriate test red cell suspension and 2 vol. of $1.2 \%$ trypsin.

Detection of Red Cell Sensitization (Direct Trypsin Reaction).- The cells to be tested are washed three times in saline and made up to a $10 \%$ suspension. Two tests can be performed, the second giving increased sensitivity.

Trypsin-saline.-One volume of the cell suspension is placed in a tube, 2 vol. of saline added and then 2 vol. of $1.2 \%$ trypsin.

Trypsin-albumin-plasma.-One volume cell suspension is placed in a tube, 2 vol. albumin-plasma mixture is added, and the 2 vol. $1.2 \%$ trypsin.

Macroscopic and microscopic readings are taken after two hours' incubation. The final readings are made without centrifuging by gently tapping the tubes to resuspend the sedimented red cells. Agglutinations have been recorded as: $4=$ solid clump of cells, $3=a$ few large clumps, $2=$ fairly numerous medium-sized clumps, $1=$ scattered fine agglutinates, and $\mathbf{M}=$ microscopic readings graded by plus signs.

\section{Detection of Incomplete Antibodies in Sera}

It was realized that at least two factors would need consideration. In the first place, since it seemed likely that the optimal incubation time would lie between one and two hours, it was feared that this might result in non-specific agglutination due to overtrypsinization should the final concentration of trypsin in the serum-cell mixture necessary for satisfactory agglutination prove to be high. 
Secondly, the presence of trypsin inhibitor in normal sera meant that an increased concentration of trypsin would be needed, and furthermore it was thought that a critical concentration might prove necessary in order to achieve maximum sensitivity.

Relationship between Trypsin Concentration and Non-specific Agglutination by Normal Sera.-U Using the standard trypsin test, there are optimal conditions for the trypsin modification of the test cells, and the strength of the trypsin solution is important. When used in weak concentrations it modifies the red cells so that they are specifically agglutinated by saline dilutions of homologous antibodies. However, as shown by Wheeler, Luhby, and Scholl (1950), when used in progressively higher concentrations the red cells are altered so as to become agglutinable by most normal sera and finally by saline. They demonstrated that from $0.4 \%$ upwards non-specific effects occurred in most sera, and at a concentration of $1.6 \%$ the red cells agglutinated even in normal saline.

With the "concurrent method" using the techniques given in which the minimal serum dilution is $1: 2.5$, this non-specific reaction does not present any difficulties provided the readings are made without centrifuging, and it has not occurred in the many sera tested using a wide range of final trypsin concentrations from 0.23 to $0.72 \%$. If the tubes are centrifuged the positives are markedly accentuated, but associated with this in many cases there also results a fine diffuse "cayenne-pepper type" agglutinate of non-specific character in a number of the previously negative tubes. This should not lead to error, since it needs little experience to differentiate it from true agglutination. The agglutinate is very easily dispersed by tapping the tube, and washing twice in saline causes these false agglutinates to disperse, whereas true agglutination persists, and in most cases is more distinct. This reaction would appear to depend upon "stickiness" of the red cells causing them to adhere under the influence of centrifugal force in the presence of serum. As distinct from this reaction, an occasional antenatal serum will give a clear-cut agglutination if centrifuged after incubation. This disappears when the tube is replaced in the water-bath, and is due to the presence of incomplete cold antibody which can be shown to occur in higher titre than normal and active over a wider thermal amplitude in a few cases during pregnancy.

Influence of Trypsin Concentration on Specific Iso-agglutination in Antigen-antibody Mixtures.With final trypsin concentrations ranging from 0.033 to $0.08 \%$ the inhibitory effect of serum was evident. There was complete blocking with absence $\overrightarrow{\overrightarrow{\vec{\rho}}}$ of agglutination at $0.033 \%$, and this was followed $\frac{7}{0}$ by a progressively lessening blocking effect as the $\frac{0}{\sigma}$ trypsin strength was increased, although even at $\frac{\bar{c}}{\bar{s}}$. $0.08 \%$ agglutination was still absent when the serum $\widetilde{\nabla}$ dilution was less than $1: 8$. Moreover, the agglu- $\frac{2}{2}$ tinates were weak and only microscopic, and the titre of the serum very low compared with other $\overrightarrow{0}$ methods.

Further tests were made with considerably higher trypsin concentrations, using strong and weak albumin anti-D sera and Group $O R_{1} r$ and $I r$. cells. The results as shown in Tables $I$ and Ir

TABLE I

INCOMPLETE ANTI-D FINAL TITRE $1: 256$ BY STANDARD TRYPSIN TEST

\begin{tabular}{|c|c|c|c|c|c|c|c|}
\hline \multirow{2}{*}{$\begin{array}{c}\text { Final } \\
\text { Trypsin } \\
\text { Concer- } \\
\text { tration (\%) }\end{array}$} & \multicolumn{7}{|c|}{ Final Serum Dilutions } \\
\hline & $1 / 5$ & $1 / 10$ & $1 / 20$ & $1 / 40$ & $1 / 80$ & $1 / 160$ & $1 / 320$ \\
\hline $\begin{array}{l}0.133 \\
0.166 \\
0.24 \\
0.32 \\
0.40 \\
0.48 \\
0.60 \\
0.72\end{array}$ & $\begin{array}{l}3 \\
3 \\
3 \\
3 \\
3 \\
3 \\
3 \\
2 \\
2\end{array}$ & $\begin{array}{l}2 \\
3 \\
3 \\
3 \\
3 \\
3 \\
3 \\
2\end{array}$ & $\begin{array}{l}2 \\
2 \\
2 \\
3 \\
3 \\
3 \\
2 \\
2\end{array}$ & $\begin{array}{l}1 \\
1 \\
2 \\
2 \\
3 \\
2 \\
2 \\
2\end{array}$ & $\begin{array}{c}\mathbf{M}+ \\
1 \\
1 \\
1 \\
1 \\
1 \\
2 \\
1\end{array}$ & $\begin{array}{c}\overline{M_{+}} \\
1 \\
1 \\
1 \\
\mathbf{M}+++ \\
1 \\
1\end{array}$ & $\begin{array}{l}- \\
\overline{\mathbf{M}+} \\
\mathbf{M}++ \\
\mathbf{M}++ \\
\mathbf{M}++ \\
\mathbf{M}++ \\
\mathbf{M}+\end{array}$ \\
\hline
\end{tabular}

TABLE II

WEAK INCOMPLETE ANTI-D FINAL TITRE 1:4 BY STANDARD TRYPSIN TEST

\begin{tabular}{|c|c|c|c|}
\hline \multirow{2}{*}{$\begin{array}{c}\text { Final Trypsin } \\
\text { Concentration (\%) }\end{array}$} & \multicolumn{3}{|c|}{ Final Serum Dilutions } \\
\hline & $1 / 2 \cdot 5$ & $1 / 5$ & $1 / 10$ \\
\hline $\begin{array}{l}0.20 \\
0.24 \\
0.32 \\
0.40 \\
0.48 \\
0.56 \\
0.60 \\
0.72\end{array}$ & $\begin{array}{c}\overline{\mathbf{M}+}+ \\
\mathbf{1} \\
1 \\
\mathbf{1} \\
\mathbf{1}+++ \\
\mathbf{M}++\end{array}$ & $\begin{array}{c}- \\
\overline{\mathbf{M}+} \\
\mathbf{M}++ \\
\mathbf{M}++ \\
\mathbf{M}++ \\
\mathbf{M} \pm \\
=\end{array}$ & $\begin{array}{l}z \\
z \\
z \\
z\end{array}$ \\
\hline
\end{tabular}

indicate that there is an optimal trypsin concentration which ranges between 0.40 and $0.56 \%$. N Within this range, the test is sensitive and specific, giving clear-cut reasily read agglutinates. Readings 0 taken at one hour were the same, but were not $\mathrm{W}$ quite so clearly defined as at two hours. Repetitive tests on a number of different sera have proved its reliability and reproducibility of these results.

The enhancement effect of albumin-plasma $\stackrel{\mathcal{P}}{+}$ mixture was studied. Titrations were made of incomplete anti-D sera serially diluted in saline and albumin-plasma, and the results compared with those obtained by the standard trypsin and Coombs methods (Table III). It is apparent that the "concurrent method" gives as clear-cut results as the 
TABLE III

COMPARATIVE TITRATIONS OF AN INCOMPLETE ANTI-D SERUM

\begin{tabular}{|c|c|c|c|c|c|c|c|c|}
\hline \multirow{2}{*}{ Method } & \multicolumn{8}{|c|}{ Final Serum Dilutions } \\
\hline & 15 & $1 / 10$ & $1 / 20$ & $1 / 40$ & $1 / 80$ & $1 / 160$ & 1320 & $1 / \overline{640}$ \\
\hline $\begin{array}{l}\text { Coombs test } \\
\text { Trypsin test } \\
\text { Trypsin- }\end{array}$ & $\overline{+++}$ & $\overline{+++}$ & ++ & + & \pm & $\overline{\mathbf{M}++}$ & $=$ & 二 \\
\hline $\begin{array}{l}\text { saline } \\
\text { Trypsin- } \\
\text { albumin- } \\
\text { plasma }\end{array}$ & 3 & 3 & 3 & 2 & 2 & 1 & $\begin{array}{c}- \\
\mathbf{M}+++\end{array}$ & - \\
\hline
\end{tabular}

standard trypsin method, and to as high a titre. There is no marked enhancement by albuminplasma when the antibody is strong, although it does produce a definite increase in sensitivity when the antibody is weak. It seems to be of more importance for the trypsin agglutination reaction when the cells are sensitized first and subiequently trypsinized (Table IV).

\section{The Detection of Red Cell Sensitization}

For the detection of " sensitized red cells," it was thought possible that the critical concentration of trypsin might have to be increased in order that cells already coated with antibody should agglutinate maximally, because it was felt that, if the action of trypsin were to modify the surface of the red cell, this might well be impeded by the previous " coating."

In view of the fact that sensitized cells will agglutinate when suspended in an albumin-plasma or albumin-serum mixture, and also that their trypsin agglutination reaction in albumin-plasma is extremely sensitive-even more so than the antihuman globulin reaction-as shown by Dausset (1952), the effects of plasma, serum, immune human gamma globulin, bovine albumin, and plasma and serum-albumin mixtures, were studied as well as those obtained by trypsin-saline.

Influence of Trypsin Concentration on Agglutination of Sensitized Red Cells in Trypsin-saline and Trypsin Albumin-plasma.-Primary union between antibody and red cell does not affect subsequent trypsin action, and the optimal trypsin concentration remains in the 0.40 to $0.60 \%$ range. However, the importance of a colloid factor in the trypsin agglutination mechanism is clearly demonstrated by the greatly increased sensitivity of the trypsinalbumin-plasma as compared with the trypsinsaline method. Moreover, its greater sensitivity than the Coombs is also apparent and it gives a four-fold increase in titre over this method (Table IV). The potentiating factor does not reside in bovine albumin, for the agglutinations obtained using this instead of albumin-plasma mixture are no stronger than those of the trypsin-saline test. Fresh plasma and serum are equally efficacious, nor is the factor thermolabile since heat inactivation does not impair their enhancing effect. Serum which had been stored for a number of months was ineffective. Immune human gamma globulin serum produced good enhancement of the trypsin agglutination which suggests the possibility that the factor may reside in the gamma globulin fraction. It would be interesting to learn whether plasma from a case of agammaglobulinaemia would be without effect.

The agglutination of sensitized cells in varying concentrations of albumin-plasma without trypsin is much less marked, and it can be shown that the amount of albumin-plasma required for the clumping of such cells is in reverse ratio to the degree of sensitization (Dausset, 1952).

TABLE IV INFLUENCE OF TRYPSIN CONCENTRATION ON
AGGLUTINATION OF SENSITIZED RED CELLS

\begin{tabular}{|c|c|c|c|c|c|c|c|c|}
\hline \multirow{2}{*}{$\begin{array}{c}\text { Final } \\
\text { Trypsin } \\
\text { Concen- } \\
\text { tration } \\
(\%)\end{array}$} & \multicolumn{8}{|c|}{ Red Cells Coated with Decreasing Amounts of Anti-D } \\
\hline & $1 / 2$ & 14 & 18 & 16 & 132 & 164 & $1: 128$ & 1256 \\
\hline $\begin{array}{c}\text { In trypsi } \\
0.24 \\
0.40 \\
0.48 \\
0.60 \\
0.72 \\
\text { In trypsi } \\
0.24 \\
0.40 \\
0.48 \\
0.60 \\
0.72\end{array}$ & $\begin{array}{l}n \text {-saline } \\
\mathbf{M}++ \\
\mathbf{M}++ \\
2 \\
2 \\
1 \\
n \text {-albun } \\
3 \\
3 \\
3 \\
3 \\
3\end{array}$ & 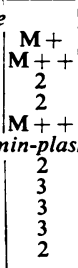 & 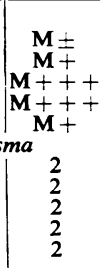 & $\begin{array}{c}\overline{-} \\
\mathbf{M}+ \\
\mathbf{M}+ \\
- \\
\mathbf{1} \\
1 \\
\mathbf{1} \\
\mathbf{M}+++ \\
\mathbf{M}++\end{array}$ & $\begin{array}{c}= \\
= \\
= \\
\mathbf{M}+ \\
1 \\
1 \\
\mathbf{M}++ \\
\mathbf{M}++\end{array}$ & $\begin{array}{c}= \\
= \\
= \\
- \\
\mathbf{M}+ \\
\mathbf{M}+ \\
\mathbf{M}+ \\
\mathbf{M}+\end{array}$ & $\begin{array}{l}= \\
= \\
= \\
\overline{\mathbf{M}}+ \\
\mathbf{M}+ \\
\mathbf{M}+\end{array}$ & $\begin{array}{l}= \\
= \\
= \\
= \\
=\end{array}$ \\
\hline$\underset{\text { Test }}{\text { Coombs }}$ & 3 & 3 & 2 & 1 & 1 & - & - & - \\
\hline
\end{tabular}

\section{Nature of the Trypsin-Agglutination Mechanism}

Absorption experiments have shown that " trypsinized cells" absorb more incomplete anti-D than fresh cells, and that this absorptive capacity can be increased (up to a certain point) when greater amounts of enzyme are used in the preliminary trypsinization (Hubinnot, 1951). Wheeler, Luhby, and Scholl (1950) have confirmed this increased absorptive capacity of " trypsinized cells."

The absorption of antibody is specific inasmuch as only those cells which contain the homologous antigen can absorb it, and that this absorption must presumably take place at specific haemagglutinogen loci on the red cell. It would thus seem reasonable to conclude that the action of trypsin is to increase 
the reactivity of these loci, and its action is therefore focal and not, as has been suggested, a generalized hypothetical digestive effect on the red ce.l membrane as a whole, or " an effect on a substance, probably a serum protein intimately bound into the surface of the red cells, possibly crystalbumin " as suggested by Wiener and Katz (1951)

Furthermore, when "enzyme-treated cells" are mixed with sensitized cells, agglutination will only take place if the enzyme-treated cells contain the specific antigenic component. If the action of trypsin were to modify the red cell surface as a whole, then one would have expected that, if such a mixture of cells agglutinated at all, agglutination would occur independently of any specific antigenantibody combination.

By using a pure saline anti-D serum or a saline anti-A, it can be shown that trypsinized cells do not absorb complete antibody more avidly than untreated ones, and, correlated with this fact, the trypsin agglutination with such sera is not remarkably different from the usual saline agglutination: in many instances it tends to be weaker.

It therefore seems logical to postulate that the increased agglutinability of trypsin-modified red cells by incomplete antibody is related to their capacity to absorb more antibody and that the effect of trypsin is to modify the antigen loci in such a way as to promote increased union between the modified loci and incomplete antibody. It would appear that fresh cells absorb complete antibody maximally and hence trypsinization has little effect.

It is proposed that agglutination depends upon a quantitative union between antigen and antibody: that a certain minimum degree of union is needed before agglutination can take place: and furthermore, that there is an optimum degree of union beyond which agglutination is not further enhanced.

It is unnecessary to postulate univalent and bivalent antibodies, and it is suggested that, in fact, all antibodies are structurally alike and are bivalent. The difference between them is a quantitative rather than a qualitative one, for, whereas the complete antibody possesses two fully reactive valencies, incomplete antibodies usually have one, on rare occasions two, weakly reactive valencies. The latter form, which has been referred to as " doubly incomplete antibody," explains those rare instances where the Coombs test is negative and only becomes positive when the cells are first trypsin-treated.

With complete antibody union is optimal, but with incomplete antibody the antigen-antibody union is sub-minimal (sensitization) and so agglutination cannot take place although a certain amount of antibody has been absorbed. Trypsin modifies the antigenic loci so that increased union between these modified loci and the weakly reacting valence of the incomplete antibody can take place.

Sensitized cells suspended in trypsin-saline will only agglutinate feebly and to low titre, but their suspension in trypsin albumin-plasma greatly enhances sensitivity and strength of reaction as shown in Table IV. They will also agglutinate in albumin-plasma mixture alone though much less strongly than in the presence of trypsin. It can also be shown that the substitution of immune human gamma globulin for albumin-plasma in the trypsin test will effect similar enhancement of the agglutination reaction, whereas bovine albumin is without effect.

Thus it is apparent that, for optimal specific trypsin agglutination to occur, at least two factors are needed: (i) Trypsin modification of the red cells, probably a focal action at the haemagglutinogen loci, optimal trypsin concentration and incubation time being necessary. (ii) The potentiating effect of a "colloid factor," possibly a gamma globulin fraction. This colloid factor does not have any direct action on the red cells. It presumably acts as a complementary factor or linkage, in the presence of which the weakly reacting valence of the incomplete antibody is enabled quantitatively to increase its union with the unchanged antigen loci to a degree sufficient for agglutination to take place.

\section{Application of the Concurrent Trypsin-tube Test to Routine Clinical Studies}

Opportunities for clinical trial have been limited $\delta$ to the study of its value and reliability as a sensitive method for routine $\mathrm{Rh}$ grouping, and for the 음 detection of incomplete antibodies in sera, but the $D$ results obtained have been encouraging and the method is so simple and easy to perform. One of No the reasons why the standard trypsin test has not been generally used may be because of the extra manipulations involved, and so the clinical results $\omega$ with the concurrent trypsin tube test may be of interest.

Routine Rhesus Grouping.-A series of $1,000 \stackrel{\mathscr{\Phi}}{\Phi}$ bloods have been tested in parallel by the trypsinsaline and standard saline tube tests.

The incomplete anti-D serum for the trypsin test $\frac{\text { Dे }}{\mathbb{D}}$ is used suitably diluted. If desired, each new batch $\frac{?}{\mathbb{D}}$ of albumin anti-D can be titrated and the dilution 2 chosen which gives strong and clear-cut agglutination with $\mathrm{D}+$ cells. As a routine the albumin o 
grouping serum supplied by the Lister Institute diluted 1:10 with saline has been used. This gives a final serum dilution of $1: 25$ for the actual tests.

Using such diluted serum nearly all Du bloods will show as $\mathrm{D}$ negative. The test, however, is sensitive for $\mathrm{Du}$, and one strongly reacting $\mathrm{Du}$, which was negative by the saline method, gave a weak trypsin agglutination.

Initially readings were recorded after two hours' incubation while checks were being made to determine the minimum incubation time which would not affect the reliability of the method. It was found that centrifuging the tubes after 10 minutes and then making the readings gave only $85-90 \%$ accuracy, but if the tubes were incubated for 20 minutes, then centrifuged, and replaced in the water-bath for a further five minutes, the results were the same as those obtained by the full two hours' incubation, although the latter were stronger and clearer cut. A comparison of the 20-minute and two-hour readings has been made on the last 300 blood groups without any discrepancy resulting.

All negatives were checked microscopically and this is regarded as important. The results were as follows:

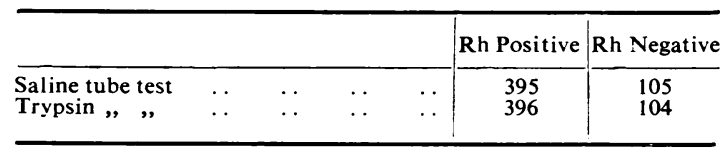

The trypsin test gave a weak positive with a sample of cord blood which was negative to the saline test. This was subsequently confirmed as a Du infant from a known Du mother.

Du Screen Tests.-The 105 rhesus-negative bloods were screened independently by one of my colleagues by the Coombs test which gave a positive reaction with six of them, one of these being the Du cord blood already referred to.

The five remaining positives were retested by the trypsin-saline method using neat, instead of diluted, albumin anti-D serum. The results show that a very weakly reacting $\mathrm{Du}$ blood was not detectable by the test, but neither did the standard trypsin test give a positive reaction with this blood. Moreover, when a $1: 2.5$ dilution of the albumin anti-D was used to sensitize the cells, the Coombs test was also negative. On the other hand, two false positives were recorded by the Coombs method which were negative in trypsin-saline. Thus emphasis is again laid upon the fact that these two tests should always be considered as complementary to one another. The results follow.

\begin{tabular}{|c|c|c|c|}
\hline & $\underset{\text { Test }}{\text { Coombs }}$ & $\begin{array}{c}\text { Trypsin- } \\
\text { saline }\end{array}$ & Remarks \\
\hline $\begin{array}{l}\text { Mrs. B. } \ldots \\
\text { Mrs. Y } \ldots \\
\text { Mrs. Ba } \ldots \\
\text { Mrs. G. .. } \\
\text { Mrs. W. . }\end{array}$ & $\begin{array}{l}+ \\
++ \\
+ \\
+ \\
+\end{array}$ & $\begin{array}{l}+ \\
++ \\
\text { Neg. } \\
\text { Neg. } \\
\text { Neg. }\end{array}$ & $\begin{array}{l}\text { Confirmed Du } \\
\text { Confirmed Du } \\
\text { Weak Du confirmed by Lister } \\
\text { Institute } \\
\text { Not Du. Cells coated with incom- } \\
\text { plete cold antibody } \\
\text { Not Du. Cold incomplete antibody }\end{array}$ \\
\hline
\end{tabular}

Routine Antibody Screening Test for Antenatal Cases.-Five hundred and thirty antenatal sera from $376 \mathrm{D}+$ and $154 \mathrm{D}$-negative mothers were screened by the trypsin-saline test. The negative sera were checked independently by the Coombs test. Antibodies were detected in five negative sera by both methods.

One case was interesting because the agglutinin was extremely weak and not present in saline or albumin. Moreover, variable results were obtained when it was tested against six different $\mathrm{D}+$ bloods, three of these being positive and three negative with both trypsin-saline and Coombs. The agglutinin was confirmed as anti-D, and it was thought that it was so weak that it could only be shown when strongly reacting $\mathrm{D}+$ cells were used. It did not react with a Du blood.

As previously mentioned, an increased incomplete cold antibody can be demonstrated in occasional cases if the tubes are centrifuged after the two-hour incubation period. The significance of its occurrence in occasional cases in pregnancy with a thermal range of activity only slightly below $37^{\circ} \mathrm{C}$. is not known, but it does emphasize the importance of using a water-bath and not an incubator when performing trypsin tests, because trypsin-treated cells are highly sensitive to cold agglutinins, and these can frequently mislead the unwary.

Antibody Titration.-The test has also been used for the study of antibody patterns during pregnancy and gives results which closely parallel those obtained by the standard trypsin method. When performed in the presence of albumin-plasma (T.A.P.) the agglutination reactions are accentuated, particularly for weak antibodies. The endpoint is clear and sharp, being usually microscopically positive only one, or at the most two, tubes higher than the naked-eye reading.

Comparative titrations of three random cases by different methods are given:

\begin{tabular}{|c|c|c|c|c|c|c|}
\hline & Saline & Albumin & A.H.G. & Trypsin & $\begin{array}{l}\text { Trypsin- } \\
\text { saline }\end{array}$ & $\begin{array}{l}\text { Trypsin- } \\
\text { albumin- } \\
\text { plasma }\end{array}$ \\
\hline $\begin{array}{l}\text { Mrs. P. } \\
\text { Mrs. A. } \\
\text { Mrs. G. }\end{array}$ & $\begin{array}{l}18 \\
\operatorname{Tr} . \\
18\end{array}$ & $\begin{array}{l}\mathrm{Nil} \\
1160 \\
15\end{array}$ & $\begin{array}{ll}14 \\
1 & 160 \\
1 & 2\end{array}$ & $\begin{array}{ll}1 & 10 \\
1 & 160 \\
1 & 5\end{array}$ & $\begin{array}{ll}1 & 5 \\
1 & 160 \\
1 & 5\end{array}$ & $\begin{array}{ll}1 & 10 \\
1 & 160 \\
1 & 20\end{array}$ \\
\hline
\end{tabular}


Direct Compatibility Tube Test.-This test is more sensitive than the usual albumin crossmatching technique and it is recommended that a trypsin-saline test at $37^{\circ} \mathrm{C}$. be included as a routine method. In one recent instance, an intra-group A incompatibility due to $a_{1}$ was readily detectable using this method.

\section{Discussion}

For the routine investigation of antenatal cases, the trypsin-saline test has proved itself to be highly sensitive, specific, and reliable, and it is considered superior to the saline or albumin methods.

It is simple and, moreover, possesses the great advantage that an albumin-agglutinating serum can be used for routine grouping of saline cell suspensions with the minimum of effort. Furthermore, the test is economical inasmuch as the grouping serum can be used diluted 10-15 times, and a capillary dropping pipette for measuring the volumes enables one 10 group five to seven bloods per drop of grouping serum.

It is desirable that $\mathrm{Du}$ bloods should not be classed as D+ on initial grouping, and this might appear to be a valid objection to the routine employment of this test. However, with diluted albumin anti-D, only a strongly reacting Du blood is likely to agglutinate, and this agglutination is weak (almost microscopic) in comparison with the strong agglutinates obtained with $\mathrm{D}+$ bloods. Such weakly reacting bloods should arouse suspicion and be checked with a saline anti-D.

An added attraction is the simplicity and speed with which all antenatal sera can be screened for the presence of antibody using a number of different test cells if desired, and, moreover, any serum found to contain antibody can be readily tested against a battery of cells of known genotypes without the labour of having to trypsinize them all separately beforehand.

As an additional precaution for cross-matching, it is ideally simple and obviates the necessity of having to perform a Coombs test, since it will detect those types of weak incompatibility which are not usually picked up in albumin.

Finally, it is suggested that it will be found to be valuable both for direct and indirect testing in haemolytic states, and the direct trypsin-albuminplasma test was positive in a recent case of acute disseminated lupus with anaemia.

\section{Summary}

A modification of the use of trypsin for routine Rhesus grouping and antibody detection with the development of two tube-tests, trypsin-saline and trypsin-albumin-plasma, is described.

The two new methods have the advantage of simplicity and save both time and labour in routine work. For Rhesus grouping the use of a diluted albumin anti-D is a great advantage and a considerable economy of serum.

Experience gained from experimental investigations and the results obtained in clinical studies have shown that the method is as sensitive, specific, and reliable as the standard trypsin and Coombs techniques, and far superior to albumin agglutination.

The marked enhancement effect of albuminplasma, especially for direct tests, is noted, and the nature of the trypsin-agglutination mechanism is discussed in the light of this.

The method is suitable for the investigation of haemolytic disease and for direct matching compatibility tests, in which latter it is considered far superior to the present albumin technique.

REFERENCES

Dacie, J. V. (1954). The Haemolytic Anaemias, p. 237. Churchill, London.

Dausset, J. (1952). Blood, 7, 818.

Delezenne, C., and Pozerski, E. (1903). C.R. Soc. Biol. (Paris), 55 327.

Hubinnot, P. O. (1951). Nature (Lond.), 167, 278.

Morton, J., and Pickles, M. M. (1947). Ibid., $159,779$.

- (1951). Journal of Clinical Pathology, 4, 189.

Wheeler, W. E., Luhby, A. L., and Scholl, M. L. L. (1950). J. Immunol., 65, 39.

Wiener, A.S., and Katz, L. (1951). Ibid., 66, 51. 